\title{
THE COMBINED EFFECT OF DEXAMETHASONE AND BACILLUS CALMETTE-GUÉRIN ON THE NEUROBEHAVIORAL ASPECT IN MALE MICE (MUS MUSCULUS)
}

\section{ABDELKRIM HAOULI, SAMIR DJEMLI*, ABDELKRIM TAHRAOUI}

Department of Biology, Applied Neuroendocrinology Laboratory, Faculty of Sciences, University Badji Mokhtar, Sidi Amar, Annaba, Algeria. Email: s_djemli@yahoo.fr

Received: 02 May 2019, Revised and Accepted: 25 June 2019

\section{ABSTRACT}

Objective: Our study aims to evaluate the combined effect of Bacille Calmette-Guérin (BCG) and dexamethasone (DEX) on male mice undergoing behavioral testing (forced swimming test, elevated plus maze, tail suspension test, and sucrose intake). An intraperitoneal injection of $0.2 \mathrm{ml} / \mathrm{mg}$ of BCG and $0.1 \mathrm{ml} / \mathrm{mg}$ of DEX body weight was administered after all behavioral tests were applied.

Methods: This study is based on the distribution of 15 male mice in three groups: Controls, DEX, and DEX+BCG. These mice underwent behavioral tests.

Results: The result after administration of DEX and BCG was found after 10 days. We observed an increase in locomotors activity with some degree of anxiety.

Conclusion: This allowed us to conclude that the combination of DEX+BCG seems to play a depressinogenic effect that will develop to become antidepressive.

Keywords: Mice, Bacille Calmette-Guérin, Dexamethasone, Behavioral, Depressinogenic, Antidepressive.

(C) 2019 The Authors. Published by Innovare Academic Sciences Pvt Ltd. This is an open access article under the CC BY license (http://creativecommons. org/licenses/by/4. 0/) DOI: http://dx.doi.org/10.22159/ajpcr.2019.v12i8.32609

\section{INTRODUCTION}

Anxiety is often used as a synonym for the word "stress." There is no universally accepted definition of it. Some authors have defined it as a complex emotional state, a combination of feelings of fear, apprehension, and anxiety, often accompanied by instability or tension [1].

Disorders of various origins can accompany anxiety, leading to behavioral problems, affecting, for example, about $30 \%$ of the inhabitants of industrialized countries [2] and appear to be progressing. In rodents, anxiety is defined as a high level of apprehension of a new and unknown environment and of the increased reaction of fear [3-5]. When anxiety becomes abnormally intense, repetitive, prolonged, and inevitable, it can present a pathological form, leading to repressed behaviors, conditioned negative responses, and poor coping strategies [6,7].

First, we test the effect of Bacille Calmette-Guérin (BCG) on the neurobehavioral aspect of male mice.

The biliary vaccine of Calmette and Guérin, most commonly referred to as BCG vaccine, against tuberculosis. It is prepared from an attenuated strain of live bovine tuberculosis (Mycobacterium bovis) that has lost its virulence on man by special cultivation on artificial environments for years. This bacillus close to Mycobacterium tuberculosis, responsible for human tuberculosis, confers sufficient cross-antigenicity to become an effective vaccine for the prevention of human tuberculosis. It has also been used in veterinary medicine. The efficacy of the BCG vaccine has been the subject of a recurrent debate due to divergent test results [8].

The second step in our experiment was to see the combined effect of BCG and dexamethasone (DEX) on male mice (neurobehavioral aspect). It should be noted that DEX is a synthetic glucocorticoid hormone and has an anti-inflammatory effect and immunosuppressant (its potency is about 40 times that of cortisol) and is sometimes illegally used with other doping and anabolic agents in farms to make animals grow faster by increasing the protein content of meat [9].
The objective of this present study is examined the combined effect of BCG and DEX on the neurobehavioral aspect in male mice (Mus musculus)

\section{METHODS}

\section{Group distribution}

Our biological material is the white male mice M. musculus, aged 6 months and average weight of $38 \mathrm{~g} \pm 50 \mathrm{~g}$ from the Pasteur Institute of Algiers.

The animals are reared in polyethylene cages. They undergo an adaptation period of 4 weeks under the environmental conditions of the experimental room (natural photoperiod, humidity, and temperature). Their food consists of corn, barley, and milk and supplements Vitamins (GAE: Agricultural Group of the East, El Harrouch, Algeria). The mice are subjected to a natural photoperiodic regimen. Due to the extreme susceptibility of stress response systems to all kinds of aggression, we attach the almost importance to daily handling conditions and to the environment where noise is attenuated. Animal procedures were performed in accordance with the Ethics Committee of the National Research Center and followed the recommendations of the National Institutes of Health Guide for Care and Use of Laboratory Animals [10].

We selected 15 males according to weight (between 32 and $44 \mathrm{~g}$ ) and we divided them into three experimental groups, five mice in each group: A control group, a group treated with DEX, and group treated with $\mathrm{DEX}+\mathrm{BCG}$

\section{Administered doses}

$D E X$

DEX is a type of corticosteroid medication. We injected a dose of DEX $0.1 \mathrm{mg}$ [11] for each mouse during the first 10 days of the period of experimental protocol, after 10 days, we repeated behavioral tests (forced swimming test [FST], tail suspension test [TST], elevated plus maze (EPM), and sucrose test). 
$B C G$

BCG is a widely used tuberculosis vaccine derived from a non-infectious strain of bovine tuberculosis (M. bovis) and mainly administered to young children.

We injected a dose of BCG $0.2 \mathrm{mg}$ [12] for each mouse during the first 10 days of the period of experimental protocol, after 10 days, we repeated behavioral tests (FST, TST, EPM, and sucrose test).

\section{Neurobehavioral tests}

FST

The FST is a behavioral model that predicts the effectiveness of antidepressant therapy [13-16]. This animal model, which is used in rats as well as in mice, nevertheless, has procedural differences depending on the species used. The test consists in placing the mouse in an aquarium $60 \mathrm{~cm}$ high by $20 \mathrm{~cm}$ wide. These dimensions make it possible to ensure that the rat cannot escape by clinging to the edges of the device. The aquarium is filled with $25^{\circ} \mathrm{C}$ water. The height of the water reaches $35 \mathrm{~cm}$ to ensure that the smile does not use its lower limbs to remain on the surface and, therefore, oblige it to swim. After a period of vigorous activity (adaptation time), the control animal stops swimming and freezes, adopting a behavior of despair. It is considered that the animal is immobile when it floats in a horizontal position and realizes only movements of small amplitude, sufficient to keep its head out of the water (Fig. 1).

The test lasts $6 \mathrm{~min}$, but only the past $4 \mathrm{~min}$ of the test are used to record the swimming time. The variables are measured on the FST: Immobility time, swimming time, and climbing time.

\section{$E P M$}

The EPM test is used to measure the degree of anxiety in laboratory animals. The test uses an elevated, plus-shaped (+) apparatus with two open and two enclosed arms. The behavioral model is based on the general aversion of rodents to open spaces [17]. This aversion leads to the behavior termed a preference for remaining in enclosed spaces or close to the edges of a bounded space. In the EPM, this translates into the animals limiting their movement to the enclosed arm. Anxiety reduction is indicated in the plus maze by an increase in the proportion of time spent in the open arms (time in open arms/total time in open or closed arms), and an increase in the proportion of entries into the open arms (entries into open arms/total entries into open or closed arms). The total number of arm entries and number of closed-arm entries are sometimes used as measures of general activity $[17,18]$ (Fig. 2).

TST

In 1985 (Steru et al., 1985) used the caudal suspension test for measures the immobility of the animal. A scotch is placed at the end of the caudal part of the animal, which allows suspending it by the tail to a hook. The hook is connected to a sensor that records movement variations for 6 min (Fig. 3).

After a period of exhaust mobility, the animal becomes immobilized and adopts a so-called despairing behavior [19].

\section{Sucrose preference test (Sucrose intake)}

This test is used only in indicator of anhedonia (lack of interest in rewarding stimuli), which is present in some forms of affective disorders including depression.

Before starting the test, rats are accustomed to the presence of two bottles of beverage (one containing water+sucrose and the other containing ordinary water) for 3 days in their cage. Following this acclimatization, the mice have the free choice of the solution either potable of sucrose or water for a period of 4 days. Water and sucrose solution is measured daily, and the positions of two bottles are switched daily to reduce any confound produced by side polarization. Sucrose preference is calculated as a percentage of the sucrose intake volume relative to the total volume of fluid intake and on average over the four test days [20] (Fig. 4).

\section{Statistical analysis}

Data are presented as mean \pm standard error of the mean. Data were analyzed by one-way analysis of variance (ANOVA) and Student's t-test. Results were considered statistically significant at $\mathrm{p}<0.05$. GraphPad Prism 6 was used to do the analysis.

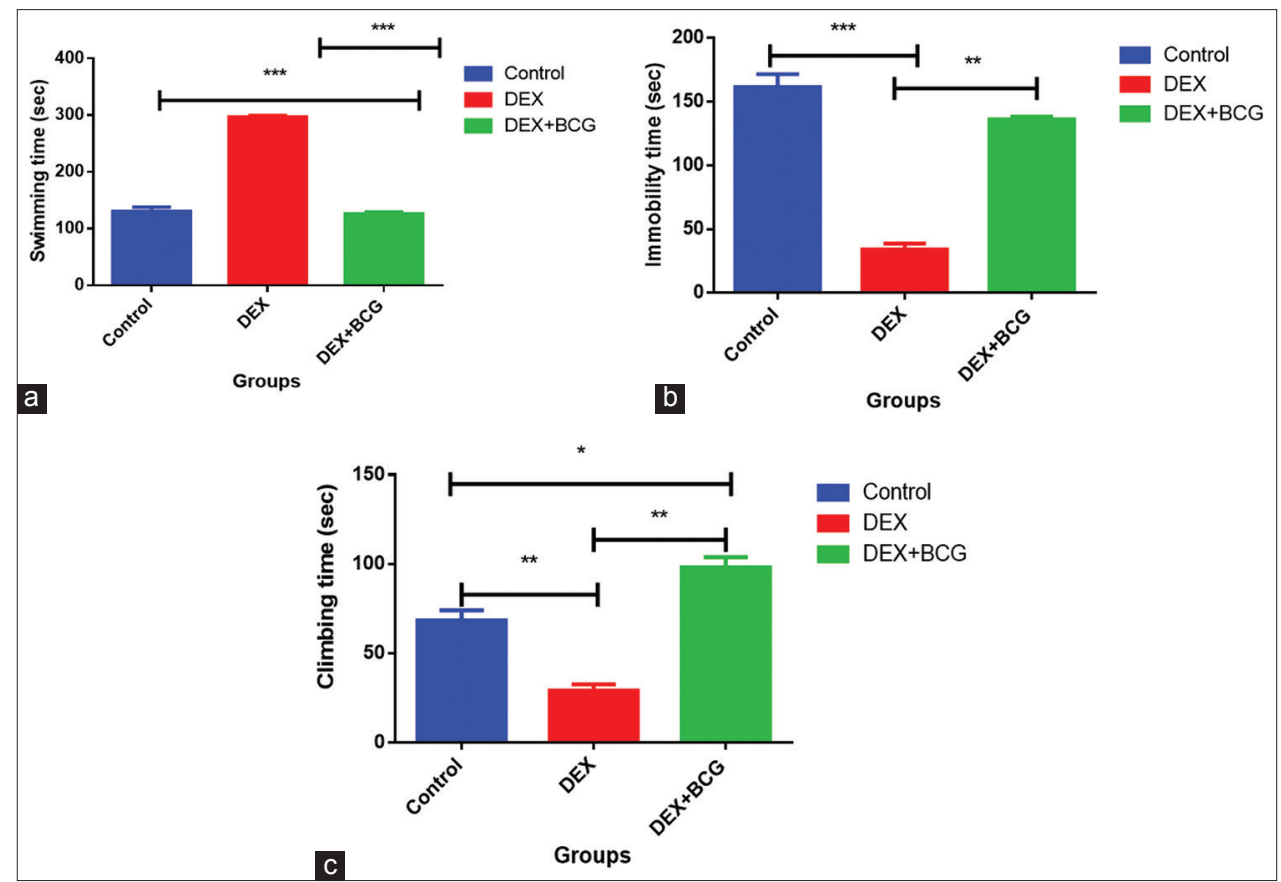

Fig. 1: Evolution of forced swimming test parameters: Immobility time (a) (sec), swimming time (sec) (b), and climbing time (sec) (c) in control, dexamethasone (DEX) group, and DEX+BCG group. Data are presented as mean \pm standard error of the mean. Data were analyzed by one-way analysis of variance and test $t$ of Student. Results were considered statistically significant at $p<0.05(n=5)$. 


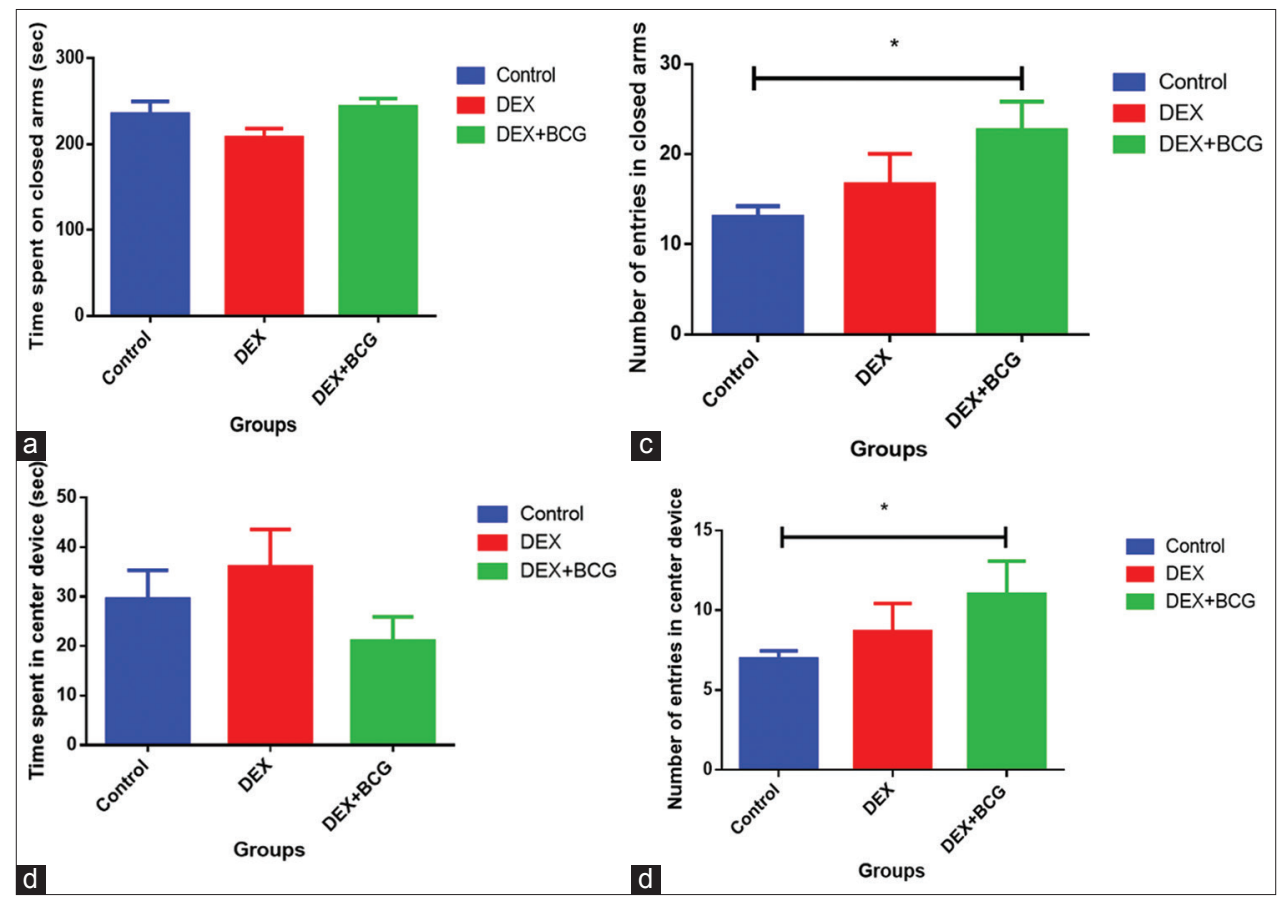

Fig. 2: Elevated plus-maze test parameters in control, dexamethasone (DEX) group, and DEX+Bacille Calmette-Guérin (a): Time spent in closed arms (sec), (b) number of entries in closed arms, (c) time spent in center device (sec), (d) number of entries in center device. Data are presented as mean \pm standard error of the mean. Data were analyzed by one-way analysis of variance and Student's t-test. Results were considered statistically significant at $\mathrm{p}<0.05(n=5)$

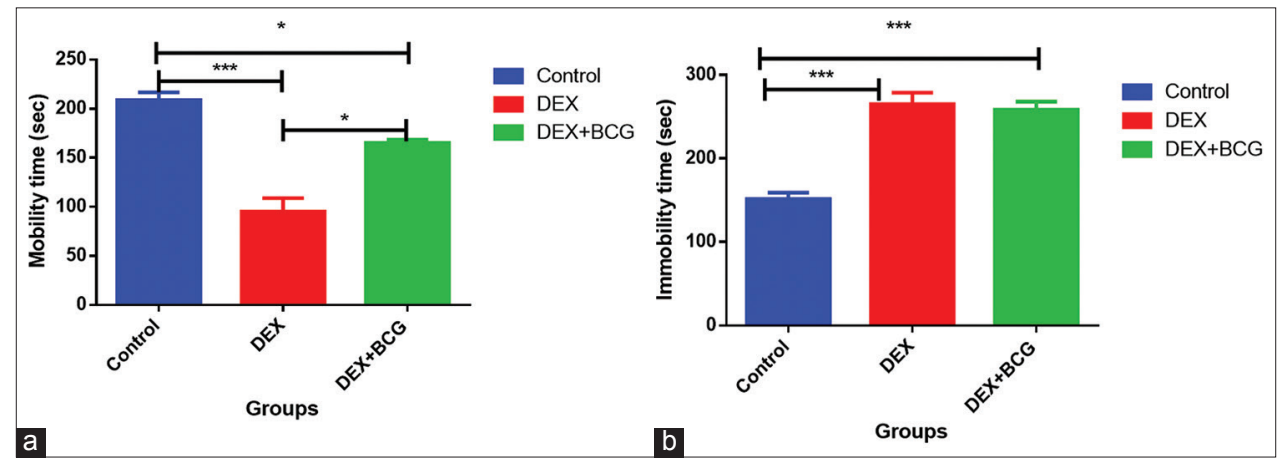

Fig. 3: Tail suspension test parameters in control mice, dexamethasone (DEX) treated, and DEX+Bacille Calmette-Guérin. (a) Mobility time (sec), (b) immobility time (sec). Data are presented as mean \pm standard error of the mean. Data were analyzed by one-way analysis of variance and Student's t-test. Results were considered statistically significant at $p<0.05(n=5)$

\section{RESULTS}

\section{FST parameters}

The measured elevated plus maze (EPM) parameters are: Swimming time (sec), immobility time (sec), and climbing time (sec) in control, DEX group, and DEX+BCG group.

\section{Swimming time}

We used one-way ANOVA and Student's t-test. The results obtained (histograms A) show that the time of the swimming in the controls is lower than that of the treated by DEX and slightly higher than that of the treatments by DEX+BCG.

The analysis of swimming time revealed a significant effect $(\mathrm{p}<0.05)$.

\section{Immobility time}

We used one-way ANOVA and Student's t-test. The results obtained (histogram B) show that the time of the immobility in the controls is greater than that of the treated by DEX and also superior to that of the DEX+BCG treatments.
Analysis of the immobility time revealed a significant effect $(\mathrm{p}<0.05)$.

\section{Climbing time}

We used one-way ANOVA and Student's t-test. The results obtained (histogram C) show that the climbing time in the controls is greater than that of the treated by DEX and lower than that of the treatments by DEX+BCG.

Analysis of the immobility time revealed a significant effect $(p<0.05)$.

\section{The EPM test}

The measured parameters are: EPM test parameters in control, DEX group, and DEX+BCG: (A)Time spent in closed arms, (B)numbe of entries in the closed arms, (C) time spent in center device, and (D) number of entries in center device.

\section{Time spent in closed arms}

The results obtained (histogram A) show that the time spent in the closed arms of the device in the controls is greater than that of the treated by DEX and lower than that of the treated with DEX+BCG. 
Analysis of the time spent in the closed arms revealed no significant effect $(\mathrm{p}<0.05)$.

\section{Number of entries in closed arms}

The results obtained (histogram B) show that there is an increase in the number of entries in the closed arms of the DEX-treated group compared to the controls and an increase in the DEX+BCG-treated group compared to the controls as well.

The analysis indicates that there is a significant effect $(\mathrm{p}<0.05)$.

\section{Time spent in center device}

The results obtained (histogram C) show that the time spent in the center of the device in the controls is lower than that of the DEX group treatments and slightly higher than that of the DEX+BCG group treatments.

Analysis of time spent in the center revealed no significant effect $(\mathrm{p}<0.05)$.

Number of entries in center device

The results obtained (histogram D) show that there is an increase in the number of entry (NE) in the center of the treatments by DEX compared

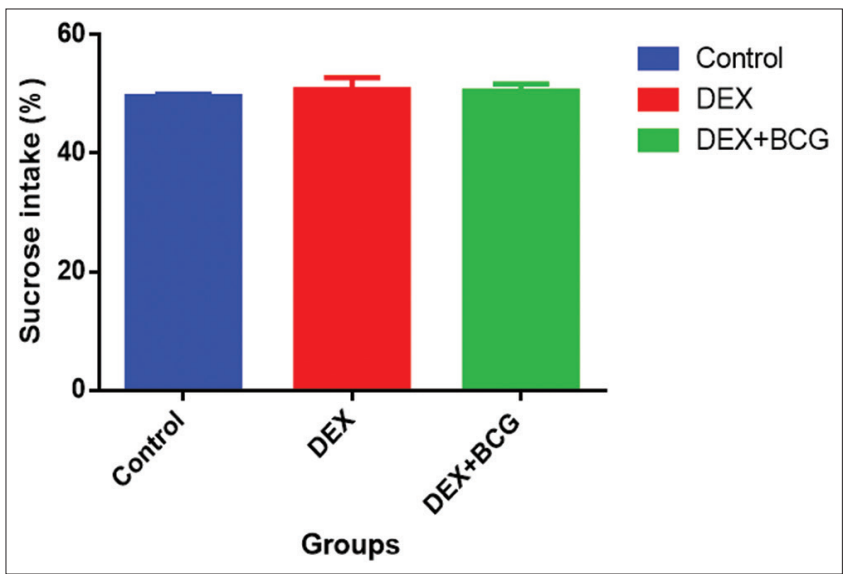

Fig. 4: Sucrose intake (\%) Parameters in control mice, treated with dexamethasone (DEX), and group treated with DEX+Bacille Calmette-Guérin. Data are presented as mean \pm standard error of the mean. Data were analyzed by one-way analysis of variance and Student's t-test. Results were considered statistically significant at $\mathrm{p}<0.05(\mathrm{n}=5)$

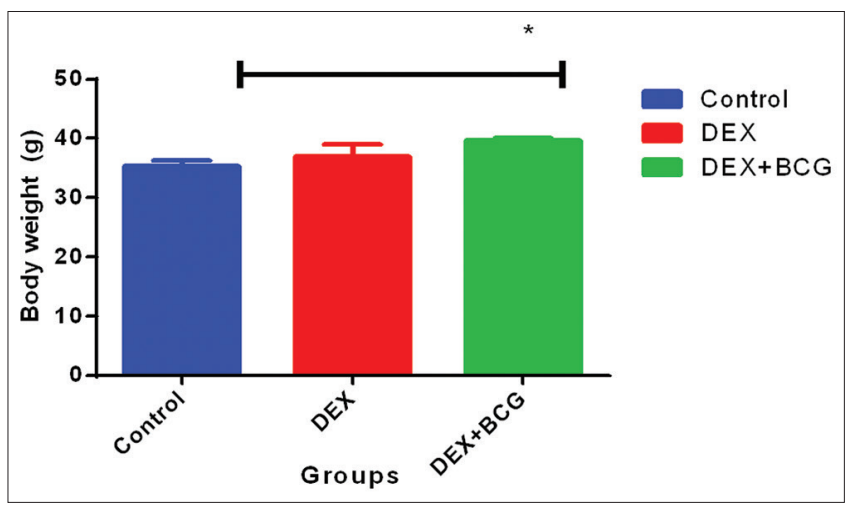

Fig. 5: Body weight (g). In control mice, treated with dexamethasone (DEX), and group treated with DEX+Bacille Calmette-Guérin. Data are presented as mean \pm standard error of the mean. Data were analyzed by one-way analysis of variance and Student's t-test. Results were considered statistically significant at $\mathrm{p}<0.05(\mathrm{n}=5)$ to the controls, and an increase of the treatments by DEX+BCG group compared to the controls as well.

The analysis indicates that there is a significant effect $(\mathrm{p}<0.05)$.

TST

The measured tail suspension test parameters are: in control mice, DEX treated, and DEX+BCG.(A) Mobility time (sec),(B) immobility time (sec).

\section{Mobility time}

The results obtained (histogram A) show that the mobility time in the controls is greater than that of the treated by DEX and also superior to that of the DEX+BCG treatments.

The mobility time analysis revealed a significant effect $(\mathrm{p}<0.05)$.

Immobility time

The results obtained (histogram B) show that the time of the immobility in the controls is lower than that of the treated by DEX and also lower than that of the treatments by DEX+BCG group.

Analysis of the immobility time revealed a significant effect $(\mathrm{p}<0.05)$.

\section{Sucrose intake test}

The measured sucrose intake parameters are: in control mice, DEX treated and DEX+BCG treated group.

The results obtained (histogram A) show that the sucrose intake test for the controls is lower than that of the treated by DEX and also lower than that of the treated by DEX+BCG.

The analysis revealed no significant effect $(\mathrm{p}<0.05)$.

Body weight

The measured body weight parameters in control, DEX treated, and DEX+BCG treated group.

The results obtained (histogram A) show that the body weight of the controls is lower than that of the treated by DEX and also lower than that of the treatments not DEX+BCG.

The body weight gain analysis revealed a significant effect $(\mathrm{p}<0.05)$.

\section{DISCUSSION}

Anxiety is considered evil of the $21^{\text {st }}$ century and its adverse effects will increasingly increase in the current model of our society. It affects oneeighth of the total population of the world and has become an important field of research in neurobiology and psychopharmacology in recent years [20]. It generates stress: Hypervigilance and the anticipation of danger keep the subject constantly alert to the presence of hypothetical stressors.

Stress is very closely related to anxiety. In many articles, the words stress and anxiety overlap. Anxiogenic situations become almost a subcategory of stressful situations [9].

In rodents, anxiety is defined as a high level of apprehension of a new and unknown environment and of the increased reaction of fear [3,5]. When anxiety becomes abnormally intense, repetitive, prolonged, and inevitable, it can present a pathological form, leading to repressed behaviors, conditioned negative responses, poor coping strategies, and an increase in the sympathetic level of the autonomic nervous system [6].

In our experimental study, we evaluated the combined effect of DEX and BCG in male mice (M. musculus) that underwent behavioral testing (FST, EPM, TST, EPM, and sucrose test). 
For the first test, which is forced swimming (FST), we observed an increase in immobility time in the batch treated with DEX+BCG compared to the control batch and a decrease in the immobile time of the batch treated with DEX compared to the control group. Therefore, the DEX causes an antidepressant effect, whereas the BCG acts in depressinogen at first; then, it will go directly to an antidepressant effect (Fig. 1).

Forced swimming, testing the effectiveness of antidepressants, represents a situation [21-27]. Mice also show active behaviors such as swimming and climbing. Molecules that decrease immobility time in forced swimming are considered to be effective antidepressants $[15,28]$. During the test of FST, antidepressants, producing a predominant noradrenergic or dopaminergic elevation, reduce immobility by increasing climbing time [29]. On the other hand, those which activate 5 -hydroxytryptamine (5HT) instead reduce immobility by the increase in swimming [30-32].

Connor et al. (1997) [17] were able to characterize corticotropin and immune responses and examine neurotransmitter levels in five regions of the brain at time intervals of 5, 30, 60, 90, and 120 min following forced swimming. They noted a significant and transient concentrations of noradrenaline and 5HT at the hypothalamus, 15 min after FST. The turnover of 5-HT significantly increased between 20 and $120 \mathrm{~min}$ in the frontal cortex and amygdala. Corticosterone showed a very high rate at $90 \mathrm{~min}$, whereas the total number of leukocytes decreased after $120 \mathrm{~min}$, accompanied by a reduction of the percentage of lymphocytes between 90 and $120 \mathrm{~min}$

Concerning the labyrinth test (EPM), our results showed that there was an increase in the number of entries in the closed arms of the DEXtreated patients compared to the control group and an increase in the DEX+BCG compared to controls as well (Fig. 2).

The plus-maze test is one of the most popular behavior patterns for anxiety. The increase in the number of entries and the time spent in the open arms are considered to be the most representative indices of anxiolytic activity. In this device, mice normally prefer to spend much of their time in the firm arms. This behavior seems to reflect an aversion to open arms that are generated by the fear of open spaces. Drugs that increase exploration of open arms are considered anxiolytic and the reverse is true for anxiety drugs $[25,33,44]$

Glucocorticoids are known to have distinct anti-inflammatory and immunosuppressive effects. Immunosuppression of glucocorticoids is mediated by a direct cytolytic effect, inhibition of lymphocyte function, or indirectly through soluble suppressor mediators [9].

In the caudal suspension test (TST), we observed a decrease in the immobility time of the DEX-treated batch and the group treated with the DEX+BCG combination by to the reference lot. This decrease is due to the effect of BCG which acts as depressinogen than as an antidepressant [34,35] (Fig. 3).

In addition, glucocorticoids exert inhibitory effects on the gonadotropin hormone-releasing hormone hypothalamic neuron and on the gonads by causing a reduction in the sensitivity of target tissues to sexual steroids (peripheral resistance) [36]. Interestingly, during inflammation, circulating cytokines suppress reproductive functions by activating the hypothalamic secretion of corticotropin-releasing hormone and peptides derived from proopiomelanocortin and thus inhibiting ovarian and testicular steroidogenesis $[37,38]$.

It should be noted that activation of the immune system in patients is associated with an increase in the prevalence of depressive symptoms [39]. Thus, BCG induces chronic activation of the nervous system $[11,46]$

According to the sucrose test, we noticed an increase in the administered rate of the sweet drink of the DEX batch and the DEX+BCG group; this is the anhedonia index (Fig. 4).
The fact that anhedonia is one of the basic criteria for the diagnosis of major depression and that it can be induced in mice by the administration of DEX, hence, the idea that the corticosteroid plays an important role in the neurobiology of depression. For example, chronic administration of corticosterone reduces the threshold current for hypothalamic self-stimulation $[39,40]$.

The last parameter analyzed was weight (body gain), we found an increase in the weight of male mice treated with DEX and DEX+BCG; this weight gain was due to the effect of DEX (Fig. 5).

DEX is sometimes illegally used with other doping agents and anabolic in livestock to make animals grow faster by increasing meat protein levels while decreasing lipid levels [10]. It is classified as a long-acting corticosteroid $[41,45]$.

All aspects of the immune response may be affected, from the response inflammatory to the development of acquired immunity. The consequences of an environmental factor depend on the nature of the stressor and its duration (acute, repeated, or chronic), the cell type concerned (lymphocytes, macrophages, and polynuclear cells), and the compartment studied (blood, pulmonary mucosa, and digestive mucosa) [42].

If the organism is not exposed to any pathogen at the time of a stressful situation, stress-induced immunological alterations may have no effect on the health of the organism. On the other hand, if the organism must simultaneously cope with a viral or bacterial infection, stress can impair the development of an adequate immune response [43].

Finally, our results indicate that DEX causes an antidepressant effect, whereas BCG acts as a depressinogen in the first stage, then it goes directly to an antidepressant effect in the stroke of forced stroke without forgetting the prose of weight caused by the DEX.

\section{CONCLUSION}

According to our results, the intraperitoneal injection of DEX $0.1 \mathrm{mg} / \mathrm{kg}$ combined with $0.2 \mathrm{mg} / \mathrm{kg}$ BCG exerted a depressinogenic effect following antidepressant action.

The results obtained in our work show at the level of the FST which is used to measure and evaluate depression, a reduction in the swimming time of the DEX-treated batch and of the batch treated with DEX+BCG and an increase in climbing time and immobility time. Therefore, the DEX to cause depression it is a depressive molecule because it increases the time of immobility.

The results for the raised cross labyrinth (EPM) test, mice place or take refuge in closed arms and are afraid of heights when less anxious they circulate freely in the open arms of the device.

However, caudal suspension test (TST) increased the immobility time of the DEX+BCG-treated mice compared to the control batch, while decreasing the mobility time in the DEX-treated mice.

As regards the sucrose test (sweet preference), an increase in the two batches treated with DEX+BCG compared to the control

Body weight showed a remarkable increase in mice injected with DEX. Moreover, batches treated with DEX+BCG.

We conclude that the combination of DEX+ BCG seems to play a depressinogenic effect that will develop to become antidepressive.

\section{ACKNOWLEDGMENTS}

We wish to acknowledge Pr. Abdelkrim Tahraoui, Director of Applied Neuroendocrinology Laboratory, Department of Biology, University Badji Mokhtar, Annaba, Algeria, for his help support and encouragement and Pr. Ali Tahar, Department of Biology, University Badji Mokhtar, Annaba, Algeria, for his support and encouragement. 


\section{AUTHORS' CONTRIBUTIONS}

We declare that this work was done by the authors named in this article and all liabilities pertaining to claims relating to the content of this article will be borne by the authors. Dr. Samir Djemli collected and analyzed the data, wrote and prepared the manuscript. Dr. Abdelkrim Haouli conducted the experiment. Pr. Abdelkrim Tahraoui helped in the experiment.

\section{CONFLICTS OF INTEREST}

The authors declare that they have no conflicts of interest in relation to this article.

\section{REFERENCES}

1. Kuloglu M, Atmaca M, Tezcan E, Ustundag B, Bulut S. Antioxidant enzyme and malondialdehyde levels in patients with panic disorder. Neuropsychobiology 2002;46:186-9.

2. Gingrich JA. Oxidative stress is the new stress. Nat Med 2005;11:1281-2.

3. Finn DA, Rutledge-Gorman MT, Crabbe JC. Genetic animal models of anxiety. Neurogenetics 2003;4:109-35.

4. Weiss SM, Wadsworth G, Fletcher A, Dourish CT. Utility of ethological analysis to overcome locomotor confounds in elevated maze models of anxiety. Neurosci Biobehav Rev 1998;23:265-71.

5. Weiss SM, Lightowler S, Stanhope KJ, Kennett GA, Dourish CT. Measurement of anxiety in transgenic mice. Rev Neurosci2000;11:59-74.

6. Connor TJ, Kelly JP, Leonard BE. Forced swim test-induced neurochemical endocrine, and immune changes in the rat. Pharmacol Biochem Behav 1997;58:961-7.

7. Lister RG. The use of a plus-maze to measure anxiety in the mouse. Psychopharmacology (Berl) 1987;92:180-5.

8. MacIntyre CR. New developments in BCG vaccine: Implications for tuberculosis control. Epidemiol Infect 2007;135:177-80.

9. Moreau M, André C, O'Connor JC, Dumich SA, Woods JA, Kelley KW, et al. Inoculation of bacillus calmette-guerin to mice induces an acute episode of sickness behavior followed by chronic depressive-like behavior. Brain Behav Immun 2008;22:1087-95

10. NIH Guide for the Care and Use of Laboratory Animals: (a) DHEW 452 Publication No. (NIH) 8-23, Revised 1978 and (b) NIH Publication No.453-85-23, Revised. US Department of Health. United States: Educations and Welfare; 1985. p. 454.

11. Casarotto PC, Andreatini R. Repeated paroxetine treatment reverses anhedonia induced in rats by chronic mild stress or dexamethasone. Eur Neuropsychopharmacol 2007:17:735-42.

12. Cuello-García CA, Pérez-Gaxiola G, Jiménez Gutiérrez C. Treating BCG-induced disease in children. Cochrane Database Syst Rev 2013; 1:CD008300.

13. Porsolt RD, Le Pichon M, Jalfre M. Depression: A new animal model sensitive to antidepressant treatments. Nature 1977;266:730-2.

14. Porsolt RD, Anton G, Blavet N, Jalfre M. Behavioural despair in rats: A new model sensitive to antidepressant treatments. Eur J Pharmacol 1978:47:379-91.

15. Porsolt RD, Bertin AG, Blavet N, Deniel M, Jalfre M. Immobility induced by the FST in rodents: effects of agents wich modify central catecholamines and serotoninergic activity. Eur $\mathrm{J}$ Pharm 1979;57:201-10.

16. Porsolt RD. Animal models of depression: Utility for transgenic research. Rev Neurosci 2000;11:53-8

17. Pellow S, Chopin P, File SE, Briley M. Validation of open: closed arm entries in an elevated plus-maze as a measure of anxiety in the rat. J Neurosci Methods 1985;14:149-67.

18. Rodgers RJ, Johnson NJ. Factor analysis of spatiotemporal and ethological measures in the murine elevated plus-maze test of anxiety. Pharmacol Biochem Behav 1995;52:297-303.

19. Steru L, Chermat R, Thierry B, Simon P. The tail suspension test: A new method for screening antidepressants in mice. Psychopharmacology (Berl) 1985;85:367-70.

20. Bourin M, Petit-Demoulière B, Dhonnchadha BN, Hascöet M. Animal models of anxiety in mice. Fundam Clin Pharmacol 2007:21:567-74.

21. Eisenberg DM, Davis RB, Ettner SL, Appel S, Wilkey S, Van Rompay M, et al. Trends in alternative medicine use in the United States, 1990-1997: Results of a follow-up national survey. JAMA 1998;280:1569-75.

22. Kirby LG, Lucki I. Interaction between the forced swimming test and fluoxetine treatment on extracellular 5-hydroxytryptamine and 5-hydroxyindoleacetic acid in the rat. J Pharmacol Exp Ther
1997:282:967-76

23. Molina-Hernández $\mathrm{M}$, Contreras $\mathrm{CM}$, Téllez-Alcántara $\mathrm{P}$. Antidepressant-like effects of pregnancy and progesterone in wistar rats as measured in the differential reinforcement of the low-rate $72 \mathrm{~s}$ task. Psychopharmacology (Berl) 2000;151:306-11.

24. Alirachedi B, Fraia A, Frih H, Zaafour M, Guernine S, Djemli S. Gender differences in the prevalence of depression (persolt swimming test) in sciatic nerve injury model Wistar rats. Glob Vet 2015;14:790-9. Available from: https://www.idosi.org/gv/gv14(6)15/1.pdf.

25. Samir D, Asma F, Hacène F, Rachedi BA, Moncef Z, Réda D. Neurobehavioral effects of dexamethasone (inhibition of adrenal axis) in male mice Mus musculus. Glob Vet 2015;15:545-53. Available from: https://www.idosi.org/gv/gv15(6)15/3.pdf.

26. Zaafour M, Fraia A, Frih H, Guernie S, Djemli S, Rachedi BA. Assessment of steroids changes (testosterone and oestradiol) after BCG inoculation in sciatic nerve injury model (male Wistar rat). Glob Vet 2015;14:805-12. Available from: https://www.idosi.org/gv/ gv14(6)15/3.pdf.

27. Fraia A, Rachedi BA, Zouiche S, Djemli S, Frih H. Polyphenon E could improve negative disorders changes caused by chronic mild stress in male, Wistar rats. Glob Vet 2015;4:478-89. Available from: https:// www.idosi.org/gv/gv14(4)15/5.pdf.

28. Jain NS, Kannamwar U, Verma L. Ethanol induced antidepressant-like effect in the mouse forced swimming test: Modulation by serotonergic system. Psychopharmacology (Berl) 2017;234:447-59.

29. Kawaura K, Honda S, Soeda F, Shirasaki T, Takahama K. Novel antidepressant-like action of drugs possessing GIRK channel blocking action in rats. Yakugaku Zasshi 2010;130:699-705.

30. Bachmann CG, Bilang-Bleuel A, De Carli S, Linthorst AC, Reul JM. The selective glucocorticoid receptor antagonist ORG 34116 decreases immobility time in the forced swim test and affects cAMPresponsive element-binding protein phosphorylation in rat brain. Neuroendocrinology 2005;81:129-36.

31. Frih H, Rachedi BA, Djenidi R, Frih N, Tahraoui A, Bairi AM. Le ketoconazole antagonise les effets immuno-gonadotropes au test de la nage forcee chez le rat male Wistar. Can J Physiol Pharmacol 2010;88:733-44. Available from: https://www.highbeam.com/ doc/1G1-233827580.html

32. Frih H, Chettoum A, Guedri K, Frih N, Rachedi BA, Djenidi R, Fisson S. Risk factors of mood disorders (depression and anxiety) in smoking subjects; reatibility with the age of smoking initiation and inflammatory processes. Annu Res Rev Biol 2014;4:1988-2006. Available from: http://www.sciencedomain.org/abstract/3934.

33. Nic Dhonnchadha BA, Bourin M, Hascoët M. Anxiolytic-like effects of 5-HT2 ligands on three mouse models of anxiety. Behav Brain Res 2003;140:203-14.

34. Saleh LA, Hamza M, El Gayar NH, Abd El-Samad AA, Nasr EA, Masoud SI, et al. Ibuprofen suppresses depressive like behavior induced by BCG inoculation in mice: Role of nitric oxide and prostaglandin. Pharmacol Biochem Behav 2014:125:29-39.

35. Kordjazy N, Haj-Mirzaian A, Amiri S, Ostadhadi S, Amini-Khoei H, Dehpour AR, et al. Involvement of $\mathrm{N}$-methyl-d-aspartate receptors in the antidepressant-like effect of 5-hydroxytryptamine 3 antagonists in mouse forced swimming test and tail suspension test. Pharmacol Biochem Behav 2016;141:1-9

36. Rabin D, Gold PW, Margioris A. Stress and reproduction: Interactions between the stress and reproductive axis. In: Chrousos GP, Loriaux DL, Gold PW, editors. Mechanisms of Physical and Emotional Stress. New York: Plenum Press; 1988. p. 377-90.

37. Rivier C, Rivest S. Effects of stress on the activity of the hypothalamicpituitary-gonadal axis: Perioheral and central mechanisms. Biol Reprod 1991;45:523-32

38. Tsigos C, Papanicolaou DA, Kyrou I, Raptis SA, Chrousos GP. Dosedependent effects of recombinant human interleukin- 6 on the pituitarytesticular axis. J Interferon Cytokine Res 1999;19:1271-6.

39. Barr AM, Brotto LA, Phillips AG. Chronic corticosterone enhances the rewarding effect of hypothalamic self-stimulation in rats. Brain Res 2000;875:196-201

40. Nielsen CK, Arnt J, Sánchez C. Intracranial self-stimulation and sucrose intake differ as hedonic measures following chronic mild stress: Interstrain and interindividual differences. Behav Brain Res 2000;107:21-33.

41. Gorzalka BB, Hanson LA. Sexual behavior and wet dog shakes in the male rat: Regulation by corticosterone. Behav Brain Res 1998:97:143-51.

42. O'Connor JC, Lawson MA, André C, Briley EM, Szegedi SS, Lestage J, et al. Induction of IDO by bacille calmette- 
guérin is responsible for development of murine depressive-like behavior. J Immunol 2009; 182:3202-12.

43. Platt B, Schulenberg J, Klee N, Nizami M, Clark JA. A depressive phenotype induced by bacille calmette guérin in 'susceptible' animals: Sensitivity to antidepressants. Psychopharmacology (Berl) 2013;226:501-13.

44. Kouadria M, Djemli S, Tahraoui A. The protective effect of zinc and magnesium against subchronic cadmium toxicity in Wistar rats (biochemical and neurobehavioral effects). Asian J Pharm Clin Res 2019:12:217-25.

45. Garmana AN, Sukandar EY, Fidrianny I. Antihypertension study of anredera cordifolia (ten). V. Steenis extract and its fractions in rats through dexamethasone induction and nitric oxide release. Asian J Pharm Clin Res 2018;1:278-82.

46. Nath SS. Immunodiagnosis of tuberculosis using PCR and BCG vaccine based elisa. Asian J Pharm Clin Res 2013;6:211-4. 